\title{
New Year Means New Challenge
}

Dear readers,

New Year means New Challenge. At the beginning of every year it is obvious common to make New Year's resolutions. The task for this year might have become to overcome financial crisis. Ambitious objective claims great acts. Economic theorists including experts, who did not expected any arrival of financial crisis to the last minute, offer large scale of proposals. Solutions are various and very often contradictory. On the one hand there are state subsidies and more extensive regulation, and on the other hand there are cancellation of whatever regulation and adjudication of superior power for the invisible hand of the market.

As it would be the rule in economics, an extreme solution is obviously not the optimal solution. State subsidies for example in the form of scrappage program can lead to continuation in death agony of certain industry. Instead of Economic Cleanup from bad firms producing needless products and providing purposeless services, these firms will be henceforth represent an emergency for further development.

However, free market is not long ago really free market, because the process of monopolization and globalization henceforth continues. And invisible hand of the market is often the invisible hand of various groups of stakeholders. Therefore we can not give up the regulation at any time.

However politicians have a need of success especially in electoral terms, and therefore they must accept such measures which would lead to immediate solution. We have to beware of Potemkin village sui generis. Otherwise - after short time of peace and placidity - new and deeply crisis can appear.

prof. Ing. Petr Marek, CSc.

Editorial board's chairman

European Financial and Accounting Journal

and investigator of the research plan

Development of Financial and Accounting Theory and its Application in Practice from Interdisciplinary Point of View 